\title{
The role of the environmental dimension in the performance management system: A systematic review and conceptual framework
}

\section{A R T I C L E I N F O}

\section{Article history:}

Received 26 September 2020

Received in revised form

18 January 2021

Accepted 19 January 2021

Available online 1 February 2021

Handling editor: Cecilia Maria Villas Bôas de Almeida

\section{Keywords:}

Environment

Performance management system

Performance measurement

Systematic literature review

Content analysis

Conceptual framework

\begin{abstract}
A B S T R A C T
The issues of sustainable development and green practices have received increased attention in recent decades. More and more companies are moving towards a strategic approach designed to integrate environmental considerations into their strategies. Nevertheless, a difficulty still remains in the strategic alignment between the environmental dimension of sustainability and performance management system (PMS). In this context, a 'state-of-the-art' analysis of related literature was used to support future research to develop integration of effective approaches and solutions. To achieve this objective, the authors sought to develop a clear picture about the key drivers of the integration process between the environmental dimension and PMS, and to identify the missing concepts, research challenges and opportunities. The authors systematically reviewed 71 English-language scientific papers published between 2002 and 2020, and identified the missing concepts by means of content analysis. The authors found a growing trend in the 18-year period of increasing theoretical research on environmental issues, but a gap was found in developing practical solutions. The findings were used to develop a conceptual model for integrating environmental drivers that emerged from the analysis in an early stage of strategy formulation, through a scorecard-based tool aimed at supporting strategic alignment. This study provides a novel and original framework for exploring environment aspect and PMS approach. We also propose a future research agenda and useful recommendations for scholars and practitioners. It lays a firm foundation for future studies and research debates.
\end{abstract}

(c) 2021 Elsevier Ltd. All rights reserved.

\section{Introduction}

The economy, as a whole, and individual companies play significant roles in seeking to achieve the sustainable development goals (SDGs) that had been formulated by the United Nations in 2015. Emphasis on sustainable development has increased rapidly in recent decades, with particular regard to discussion on the key environmental value creation drivers in an organization's strategy (Farias et al., 2019; Chalmeta and Palomero, 2011). The awareness and importance of taking environmental consideration, as one crucial element of sustainability, into corporate strategy is well documented by company leaders, who are increasingly adopting

\footnotetext{
* Corresponding author. Dep. of Management and Law and SEEDS, Faculty of Economics, University of Rome Tor Vergata, Via Columbia, 2, 00133, Rome, Italy.

E-mail addresses: hristov@economia.uniroma2.it (I. Hristov), andrea.appolloni@ uniroma2.it (A. Appolloni), antonio.chirico@uniroma2.it (A. Chirico), wenjuan. cheng@uniroma2.it (W. Cheng).
}

environmental practices and initiatives into their business plans and strategies (Wu et al., 2018). They are working to implement urgently needed changes that must be made in the context of climate change, which continue to increase beyond what was agreed upon by leaders of nearly all countries in the 2015 Paris Agreement on Climate Change.

In this context, integration of environmental drivers in the performance management system (PMS) could help companies to obtain relevant advantages in terms of companies' performance outcomes (Bhattacharyya, 2019) and, consequently, to positively contribute to the sustainability and well-being of humans and other species on planet Earth. The relationships between environmental initiatives and different dimensions of a firm's performance have been extensively studied. Researchers have documented the positive corporate benefits of their integration of environmentally responsible actions into their business plans and strategies (Trianni et al., 2019; Genovese et al., 2017; Gond et al., 2012). 
However, some researchers have reported some weaknesses in corporate emphasis on environmental dimensions in their value creation processes (Farias et al., 2019; Morioka and de Carvalho, 2016), highlighting how an integrated environmental approach could positively impact on companies' performance. However, to place the environmental strategies in the context of the PMS and to identify related tools for integrating the environmental dimensions into these systems continues to challenge corporate stakeholders.

Two obstacles to widespread integration of environmental dimensions into the PMS were documented. Firstly, there was no clear understanding of the key environmental drivers that impact a company's performance. Secondly, there was a lack of practical support solutions for managers to implement improved environmental strategies. In spite of these needs, there was no structured approach on effective ways to identify and to integrate the key environmental drivers into their PMSs.

This 'missing element' was repeatedly underscored by many authors, who considered the environmental dimension as an integral part of the value creation process of a company that must be more effectively integrated into the PMS (Hristov et al., 2019; Liu et al., 2017; Haider et al., 2016; Figge et al., 2002). Therefore, the research problem and the stimulus for the authors of this paper aimed to contribute to overcoming these gaps in the literature and in practice.

With the objective of filling this gap, this paper included two more specific purposes: (1) to provide an updated literature review on the subject matter presenting the state-of-the-art in order to understand the current study status on the roles and benefits of integrating the environmental dimension in supporting the PMS, and (2) to identify a way to integrate environmental dimension into the PMS in order to achieve sustainable improvements, and to identify challenges for future research. Accordingly, the authors focused upon two research questions:

Rq1. What are the main trends in the literature on the relationships among the environmental dimensions/drivers and the PMS?

Rq2. What are the challenges for a "greener" PMS to be structured and implemented into a company's business models and practices?

To answer these research questions, a systematic literature review (SLR) based upon 71 papers was conducted. Relevant literature on this topic has highlighted interesting issues for the scientific community and practice. Several issues related to sustainable performance were discussed with regard to the environmental indicators and models, which focused on the accounting context and reporting (Schaltegger and Burritt, 2010; Kolk and Mauser, 2002), and on the design of measurement systems (Morioka and de Carvalho, 2016; Searcy, 2012, 2016). Several authors analyzed measurement of environmental and economic dimensions from an organizational perspective (Nawrocka and Parker, 2009; Albertini, 2013). Few authors focused specifically on the roles of environmental dimensions in the PMS based on planning, control and decision-making approaches. Hansen and Schaltegger (2016) specifically focused on the Sustainability Balanced Scorecard (SBSC), without considering the question of whether and under what circumstances the environmental aspects represented the dimensions that are essential for the PMS; rather, they highlighted some limitations and posited that the structure of the SBSC reflects the value systems. Therefore, there is a lack of managerial solutions designed to help corporate leaders to integrate environmental dimensions into their PMSs.

Accordingly, the authors answered the first research question (Rq1) by providing an overview of the environmental dimensions/ drivers considered relevant in the PMS. This contributes to the existing literature by clearly delineating practices and measures, performance outcomes, organizational drivers and critical issues linked to environmental integration in the PMS, which need to be analyzed from the management accounting perspectives.

With regard to the second research question (Rq2), the authors used the results of the review by considering the main challenges that emerged to provide guidance for the integration process. Thus, the authors of this review developed an extended four-dimensional model to build upon the existing literature. By incorporating the environmental dimensions in the early stage of the PMS cycle, strategic coherence and environmental alignment are provided that can help companies to integrate sustainable development, which is integral to their corporate business models and decisionmaking processes (Dutta et al., 2013; Crittenden et al., 2011).

Therefore, the future directions and challenges related to this research field are reviewed and discussed in this article. The model developed by this paper's authors is relevant for managers who deal with sustainability issues at strategic decision making and implementation management levels.

The paper is organized as follows: Section 1 includes the introduction of the research context, research problem, goals and research questions. Section 2 presents the key issues analyzed in this paper. Section 3 contains the research methodology. Section 4 reviews the results in terms of descriptive analysis, and Section 5 summarizes the literature. Section 6 presents the content results of the content analysis. In Section 7, the authors discuss the framework, its potential benefits and implications. Section 8 presents the conclusion and the authors make suggestions for further research.

\section{Basic concepts and framework}

\subsection{Performance management system (PMS)}

The first key issue considered in this paper is the PMS, defined as a system based on several integrated processes that support managers in decision making, for value creation in a holistic manner, by identifying several steps and processes to include in the companies' strategies (Ferreira and Otley, 2009; Armstrong and Baron, 2005). The PMS is based on different phases that allow maximum integration. In particular, in implementing a PMS, the starting point is represented by a 'strategic plan' that defines the roles, competences and strategic goals of the company. Then, implementation of the strategies defined in the previous step is required. This phase is crucial for the success of the process, as it connects planning and the operational execution of the strategy. The identification of key drivers and action plans for improvement in line with the company's strategic guidelines is a priority for the management to achieve high performance (Aguinis, 2012).

In addition, monitoring the processes enables management to receive continuous feedback and to coach and manage the system more effectively. The PMS cycle needs to be used to refine the strategic plan based on the feedback received during the strategic implementation process, which facilitates their re-review of the strategic plans, the mission of the organization and the strategic objectives. This circular approach needs to be continuously improved based on the internal and external environmental context.

\subsection{Sustainable performance development}

Addressing the second key issue of our paper, the authors focus upon integration of the PMS and the environmental dimension of sustainability. This facilitates implementation of structural sustainable development by supporting the long-term performance (Lo and Sheu, 2007). Accordingly, a crucial role is covered by the sustainable development in achieving higher quality performance 
when used as a process designed to meeting the needs of the present without compromising the ability of future generations to meet their needs (Morioka and de Carvalho, 2017; Gond et al., 2012).

Interest in sustainable development has increased as scholars have focused on the roles of corporate sustainability, defined as a business approach that creates and sustains the long-term value of a company. It embraces the triple bottom line (TBL) dimensions (economic, environmental, and social) by recognizing the urgent need for radical changes in current, unsustainable business practices (Maas and Reniers, 2014; Scavone, 2006).

Among the triple pillars of sustainability, the importance of the environmental aspects was the focal point of research by several authors (Trianni et al., 2019; Chen et al., 2017; Venturelli et al., 2017; Azevedo et al., 2012). Focus on the environmental pillar was deeply encapsulated in recent studies designed to help to improve the performance of companies' sustainability efforts ( $\mathrm{He}$ et al., 2017; Ahmadi et al., 2016; Maas et al., 2016; Trumpp et al., 2013). The authors of this paper focused on the environmental dimensions of sustainability. The environmental practices are definable in terms of performance management (Campos et al., 2015; Burritt, 2004).

Fig. 1 outlines the analytical conceptual framework used in this literature review. The authors took different integration levels into account to analyze and highlight the existing relations in the literature between environmental dimensions of sustainability and the PMS.

In the first level (I), the dashed blue oval, the environmental macro-dimensions were presented (in green). In particular, the role of emissions, consumption, renewable resources and ecoefficiency was deeply discussed in the literature. These dimensions can be considered to be integral elements of sustainability studies and are not directly connected to the PMS. The concept of sustainability is based on a new management and corporate governance model for meeting the expectations of stakeholders, as well as for fulfilling the legal obligations and beyond what is prescribed by individual ethical standards (Lee and Farzipoor Saen, 2012). Therefore, it is clear that sustainability involves company strategies and policies, interacting with all areas of company management, from production to selling, and from the management of human resources to financial aspects related to the economic dimension (Chalmeta and Palomero, 2011; Garcia et al., 2016). The environmental dimensions are no longer downgraded and considered irrelevant issues with respect to the primary objective of achieving profit, but are seen as essential tools and vehicles for achieving value creation (Bonacchi and Rinaldi, 2007).

The second level (II), grey area, highlights the relevant role assumed by the strategic models used to connect environmental dimensions and the management system. For example, the Sustainability Metrics (IChemE), the Global Reporting Initiative (GRI), the supply chain management (SCM) (Schöggl et al., 2016), and strategic management tools such as the SBSC (Hristov et al., 2019; Hansen and Schaltegger, 2018; Nicoletti Junior et al., 2018; Xia et al., 2017; Figge et al., 2002). In this part, integration is evident because the majority of the authors have explained the existing relationships based on the model provided above. In particular, the SBSC represents a "bridge" from the sustainability dimensions to the PMS based on the key performance indicators (KPIs) system, aiming to create value and, therefore, improve the performance of companies (Hubbard, 2009).

In the last level (III), dashed black oval (Fig. 1), the focus is on the basic elements of the PMS process and related phases (from Prerequisites to Performance Renewal), integrated in the strategy of the company based on the mission and vision. The system was designed to consider and evaluate all drivers and their impact on value creation. In addition, the figure illustrates the integration among the levels. Accordingly, on the left side of the figure, the sustainability (S) context is highlighted, which is fully represented in the first and second levels, and has low representation in the third level (from S+ to S-). In the same way, on the right side, the PMS context is highlighted, which is well represented in the second level, exclusively connected in the third level, and has a low presence in the first level (from PMS + to PMS-).

A good interaction point was highlighted in the second level, where the integration is the strongest. The main reason for this is that the above-mentioned strategic models can be effective tools to introduce environmental practices into organizational strategies. The selection and use of environmental KPIs is an important topic in the scientific community, based on different methodological and conceptual approaches (Genovese et al., 2017). All the dimensions analyzed in the literature have to be considered in the PMS cycle of the company, by defining, for each of them, the goals, KPIs, measures of the impact of global performance, and the process to adopt in order to achieve the goal and target (Kim and Rhee, 2012). Therefore, by incorporating environmental dimensions within the early stage of the PMS process, the strategic alignment allows an

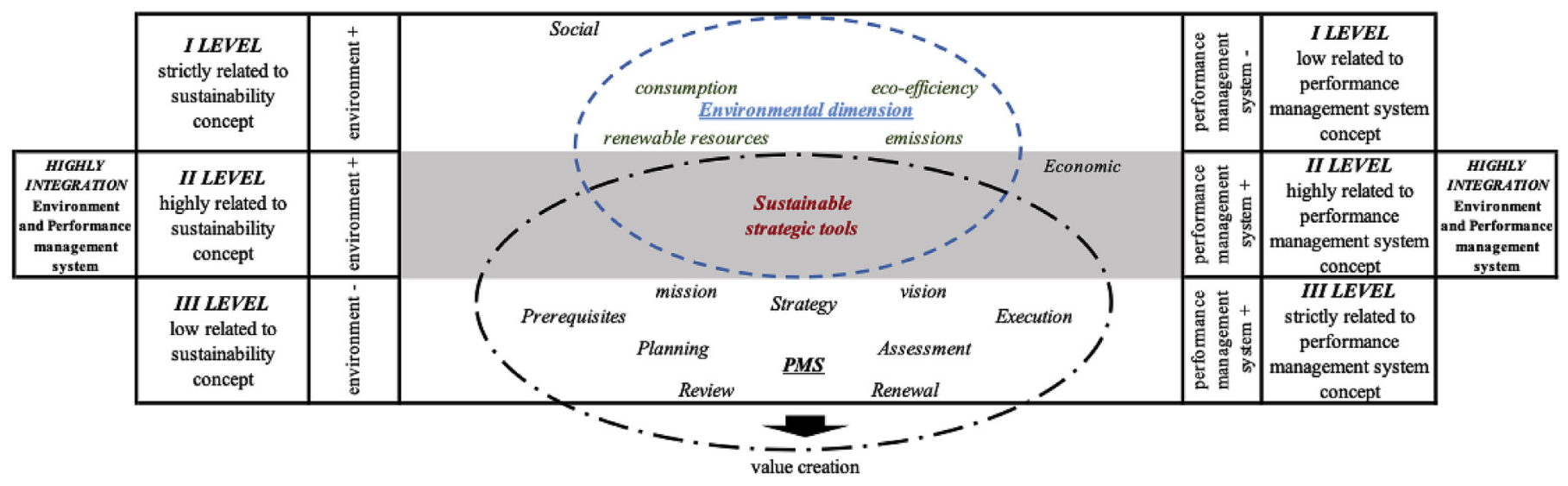

\footnotetext{
I level (environmental dimension) is high related to the sustainability concept and low related to the performance management system concept II level (integrated approach) is high related to the sustainability concept and high related to the performance management system system

.. III level (performance management system dimension) is low related to the sustainability concept and high related to the performance management system concept
}

Fig. 1. The level of integration between Environmental dimensions and PMS. 
impact on the cultural change, which leads to adopting an integrated environmental approach (Perego and Hartmann, 2009).

\section{Research methodology}

According to Seuring and Gold (2013), the scope of a literature review is to point out important streams of research, to summarize research results, to assess the knowledge base in a particular research field, and to clarify future research opportunities. To this end, our research consists of a SLR about the relationship between environmental dimensions and PMS. In particular, our paper aims to provide a structured and critical analysis on the impact that an integrated environmental-oriented PMS could have on the companies' performance. Accordingly, we adopted a systematic approach (Tranfield et al., 2003) aimed to provide rigorous and sound literature reviews on the research field (Seuring and Gold, 2013; Littell et al., 2008). In this study, we used content analysis to provide a quantitative assessment of the content of the literature reviewed for this article. In this context, we defined our search protocol step by step that allowed us to clearly define the process that led to the answers to our research questions. A SLR is useful because it guarantees an in-depth analysis of the theory analyzed by summarizing key issues that emerged and their implications.

\subsection{Search strategy}

To provide a clear picture of the topic discussed, in the first step of the systematic process, we defined a specific border to define and contextualize our research (Seuring and Müller, 2008). Thorough this rigorous process, we worked to contribute to the existing literature by generating information on the research field for new opportunities and challenges for further research (Pickering and Byrne, 2014). Our search process, as described in Table 1, was based on three main steps: 1) selection of the sample, 2) content analysis, and 3) discussion of the results. The protocol is based on different phases regarding the source material (from 1 to 5), and filters applied (from 6 to 8 ) to obtain and analyze the final sample (from 9 to 11 ).

\subsection{Selection of articles for the literature review}

The literature analyzed in this paper comprises peer-reviewed articles, which examined the relation between the environmental dimension and the PMS, from January 2002 to December 2020. We used Scopus in selecting papers. The chosen time range was selected because the literature on the role of sustainability in the PMS was given concrete attention at the beginning of the century (Figge et al., 2002). We used the asterisk in the Boolean search as a root word for all connected keywords. The selection of keywords was chosen to attempt the most representative collection of relevant records possible. The keywords used for the selection of papers were: Environment* or Green or Ecolog* or Sustainab* or EMAS or "Corporate Social Responsibility" or ISO 14001 AND "Performance Management" or "Performance Measurement" or "Balanced Scorecard" or "BSC" or PM in the article title, abstract and keywords. Based on this first approach, we obtained a total of 2284 papers.

In the second phase, based on the initial sample of articles, we made the selection based on each paper's title, abstracts and keywords. Rigorous inclusion and exclusion criteria were defined. Articles were selected if the title, abstract and keywords discussed, or at the very least referred to, environmental/PMS issues. An initial review of 2183 articles found 362 articles, which were considered for further analysis in this field of research. We used several criteria for inclusion or exclusion of the papers selected, related to the contents and to the journal. Duplications were eliminated and articles were excluded if they were published in the journals that did not focus on business management and accounting. To keep a high standard, we only considered journals that were ranked with three or four stars (top quality) by the Association of Business Schools' Academic Guide (ABS, 2018). An exception was the Journal of Cleaner Production as a trans-disciplinary journal; it is not listed in the $A B S$, but is particularly relevant for the number of papers selected (27), and this confirms the tendency of that journal to analyze the main focus of this literature review.

Based upon this approach, 247 papers were selected and analyzed. Once this sample had been selected, an additional

Table 1

Sample collection.

\begin{tabular}{|c|c|}
\hline Phase A - Sample selection & Description \\
\hline 1. Research question(s) & $\begin{array}{l}\text { a) What are the main trends in the existing literature on the relationship between the environmental dimension/drivers and the } \\
\text { PMS? } \\
\text { b) What are the challenges for a "greener" PMS to be structured and implemented into a company's business model and } \\
\text { practice? }\end{array}$ \\
\hline 2. Database & Scopus \\
\hline 3. Search field & Title, Abstract and Kws \\
\hline 4. Scientific areas & Accounting, Management and Sustainability \\
\hline 5. Date of publications & From 2002 to 2020 \\
\hline 6. Keywords & $\begin{array}{l}\text { Environment* or Green or Ecolog* or Sustainab* or EMAS or "Corporate Social Responsibility" or ISO } 14001 \\
\text { AND "Performance Management" or "Performance Measurement" or "Balanced Scorecard" or "BSC" or PM }\end{array}$ \\
\hline 7. Inclusion criteria & $\begin{array}{l}\text { a) Language: English; } \\
\text { b) Journals: Peer-reviewed journals (articles and reviews); } \\
\text { c) Topic: Only articles that describe the relationship between Sustainability and PMS; } \\
\text { d) Time span: Articles published between } 1999 \text { and } 2019 \text {. }\end{array}$ \\
\hline 8. Exclusion criteria & $\begin{array}{l}\text { a) Documents: Book chapters, magazines, conference papers, Masters and doctoral dissertations, textbooks and research reports; } \\
\text { b) Journals: } 1 \text { and } 2 \text { stars (ABS 2018); } \\
\text { c) Topic: Articles that do not describe the role of the sustainability dimension in the PMS; } \\
\text { d) Time span: Articles published before } 2002 \text {. } \\
\text { Elimination of duplicates }\end{array}$ \\
\hline 9. First screening & Articles that focus on the aim of the research. \\
\hline 10. Secondary screening & Top quality journal selection - 3 and 4 stars (ABS 2018). \\
\hline 11. Final selection & Full paper analysis. \\
\hline Phase B - Content analysis & Statistical descriptive analysis and concept depth analysis in order to answer Rq1 and Rq2. \\
\hline $\begin{array}{l}\text { Phase C-Extended conceptual } \\
\quad \text { framework }\end{array}$ & Discussion and conceptualization of the results. \\
\hline
\end{tabular}


screening was made. In this phase, the authors focused on the full paper contents, assuring that the papers selected addressed environmental dimensions (Fig. 1) related to issues of the PMS. The research questions led us to our article selection by excluding papers that were not relevant to our analysis. In the final step of our selection process, the contents of each article were carefully analyzed to guarantee that it, indeed, focused on the environment/ PMS or on one of the main related areas. In addition, each paper was read independently by the authors, ensuring the validity of the selection. Based on the full paper analysis, we selected 71 papers (Fig. 2).

\subsection{Content analysis method}

Content Analysis is a research approach to extract and analyze the information from documents in quantifiable ways to identify the trends and characterize the key features of the dataset (Harwood and Garry, 2003). This approach is widely applied in the social science field, one of which is Management (Jarden et al., 2019; Cheng et al., 2018; Kohlbacher, 2006). In our paper, this methodology was conducted by using Leximancer software (Cheng et al., 2018; Smith and Humphreys, 2006), which is a text analytics tool that applies an intelligent algorithm to iteratively build a thesaurus of concepts by analyzing collections of textual documents and to display the extracted information visually. The Leximancer algorithm is used to develop a probabilistic model for quantifying and displaying the conceptual structures of the articles reviewed, rather than performing a simple word count.

After performing the paper selection process, the authors built the dataset by providing the text sources with all the references deleted. Then, the authors input all the data into Leximancer to obtain an initial visual map. At this stage, the authors defined the maximum number of concepts as 200 so that any contributing information would not be missed. As a result, the authors obtained all the concepts that were interesting and relevant in the selected articles. Common function words that comprise a standard set of excluded words in Leximancer were obviously not accounted for (such as and, not, etc.). Moreover, closely associated words or singular and plural words were merged. Besides, the authors manually deleted the concepts that were general terms (such as ability, impacts, produce, etc.) that appeared frequently in the text but did not

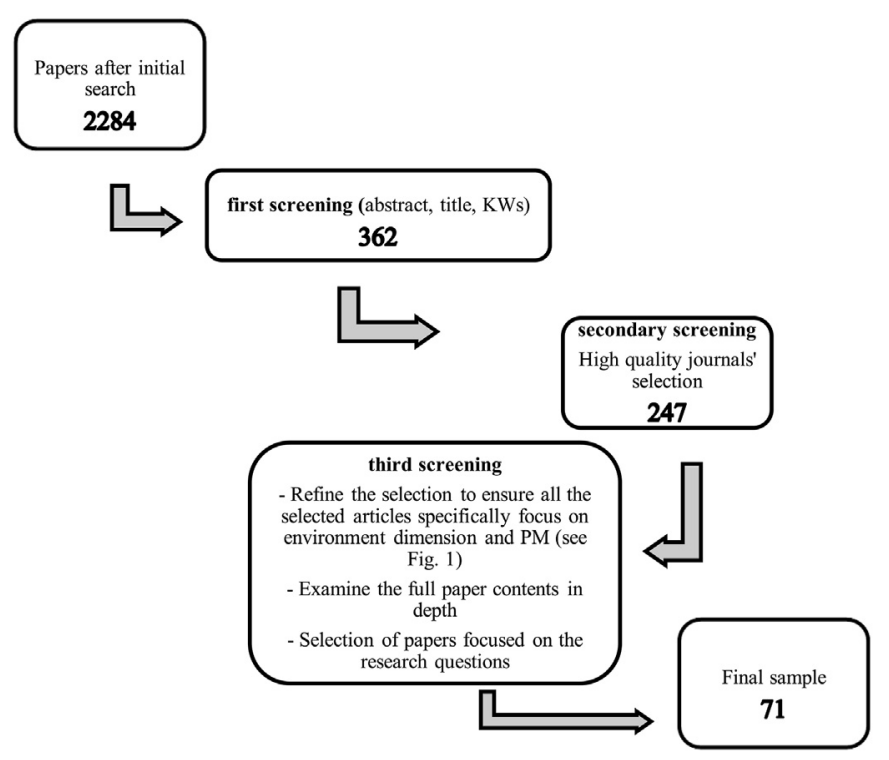

Fig. 2. Papers' selection process results for each research phase. contribute any meaning to the research. To investigate the research trends in a visual way, the content analysis was performed by dividing the dataset into three sub-periods, i.e. 2002-2007, 2008-2013 and 2014-2020.

\subsection{Objectivity and validity of review}

The SLR approach was based on the rigorous process to ensure objectivity and rigor of the research. On the basis of the approach identified by Seuring and Müller (2008), we conducted a specific procedure to guarantee rigorous research based on the continuous interaction between the authors during all steps of the analysis conducted. Each of the authors worked based on a specific process, for example, skimming the abstracts, and ensuring validity and reliability of the selection process. Secondly, the authors worked separately reading the papers and reporting their main contents in a detailed table. This approach ensured the objectivity of the research. In addition, in order to validate our work, the search protocol was compared to other structures both from within as well as from outside the specific area.

\section{Descriptive analysis}

In this section, we developed a descriptive analysis of the sample, and divided all papers based on the time period of publication, by journals/areas and research methodology. After the statistics' analysis we produced, the main concept emerged. This method is widely applied in different contexts (Hassini et al., 2012; Kohlbacher, 2006), in order to investigate relevant issues in quantifiable terms (Harwood and Garry, 2003). In the last part, the extension of the previous model (Fig. 1) was used for analyzing the challenges for any future research.

\subsection{Distribution of publications across the period}

Firstly, the authors focused upon the time distribution, from 2002 to 2020, as shown in Fig. 3. In particular, we found that the first article was published by Figge et al., in 2002 on the SBSC. This article points out the beginning of the debate on the use of the strategic management system to integrate the sustainability issue within the PMS. Fig. 3 shows the article distribution for the period considered. This period range confirmed the interest and the emphasis on the environment as a dimension related to the PMS. The majority of the articles have been published in the last ten years and there has been a gradual increase after the year 2010. There were no relevant articles published in 2003, 2005 and 2010. In the period 2015-2020, a total of 36 papers were published, twentythree in the period 2010-2014, and ten and two, respectively, in the other two clusters.

\subsection{Distribution of publications across journals}

In order to have a clear picture of the sample, we provided a summary of the journal sources selected. As stated in section 3, the authors selected 71 articles that focused on the environment dimension of sustainability and the PMS. In particular, Table 2 lists the number of articles from each journal and the percentage weight on the total of the articles, the Journal's Impact Factors (IFs), and year of publication for each journal. In addition, the 71 papers selected were divided, based on the related journal, into three main areas of interest (Cheng et al., 2018): 1) Sustainability and Environment, 2) Performance Management, Accounting and Operations Management, and 3) General Management. Area 1 contained the highest number of articles (48) published in 3 different journals. In this area, the largest number of articles was published in the 


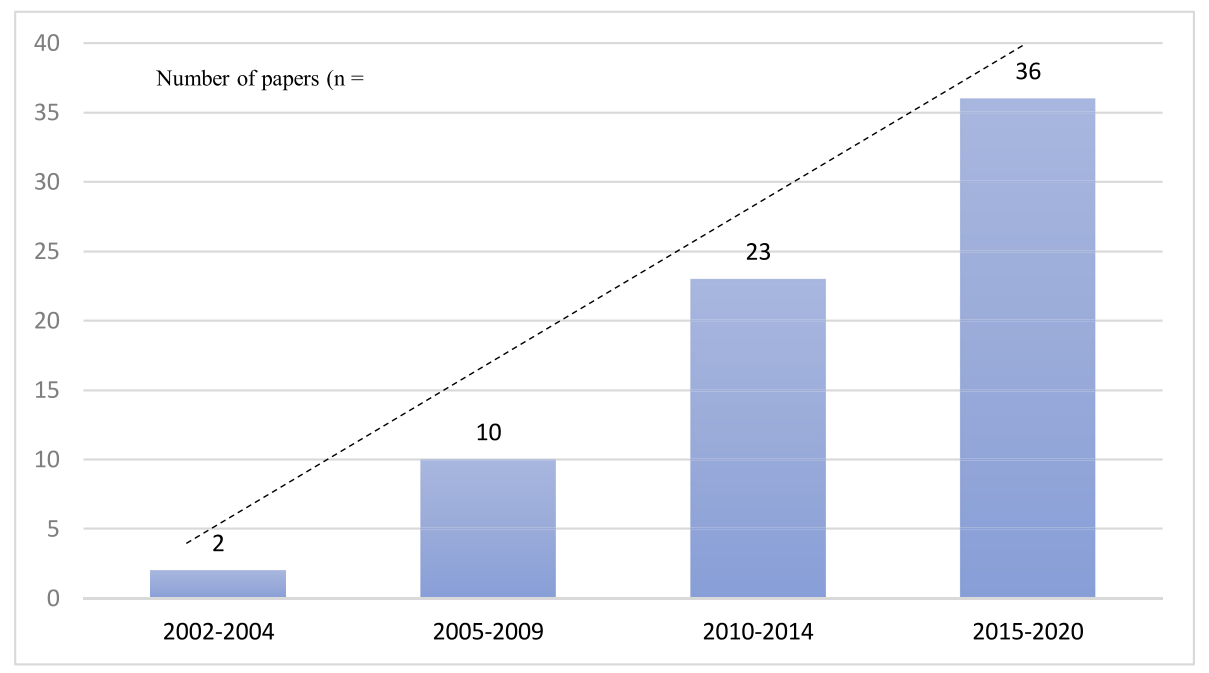

Fig. 3. Distribution of journal articles over the time period 2002-2020.

Table 2

Distribution of the papers' sample by journal and research area.

\begin{tabular}{|c|c|c|c|c|c|}
\hline Papers divided by Journal/Area & $\begin{array}{l}\text { No. of articles found } \\
(\mathrm{n}=71)\end{array}$ & Percentage & $\begin{array}{l}\text { Publication } \\
\text { period }\end{array}$ & $\begin{array}{l}\text { Impact factor } 2019-2020 \text { of the } \\
\text { Journal/Area }\end{array}$ & $\begin{array}{l}\text { ABS } 2018 \\
\text { stars }\end{array}$ \\
\hline First Area - Sustainability and Environment & 48 & $67 \%$ & $2002-2020$ & 15.520 & \\
\hline Business Strategy and the Environment & 15 & $21.1 \%$ & $2002-2020$ & 7.860 & 3 \\
\hline Journal of Business Ethics & 4 & $5.6 \%$ & $2012-2018$ & 4.141 & 3 \\
\hline Journal of Cleaner Production & 29 & $40.8 \%$ & $2006-2020$ & 7.246 & - \\
\hline $\begin{array}{l}\text { Second Area - Performance, Accounting and Operations } \\
\text { Management }\end{array}$ & 19 & $27 \%$ & $2001-2017$ & 32.653 & \\
\hline Accounting Forum & 1 & $1.4 \%$ & 2008 & - & 3 \\
\hline British Accounting Review & 1 & $1.4 \%$ & 2014 & 3.333 & 3 \\
\hline IEEE Transactions on Engineering Management & 1 & $1.4 \%$ & 2012 & 2.050 & 3 \\
\hline International Journal of Production Economics & 2 & $3.8 \%$ & $2012-2017$ & 5.134 & 3 \\
\hline International Journal of Production Research & 1 & $1.4 \%$ & 2012 & 4.210 & 3 \\
\hline Journal of Accounting and Public Policy & 1 & $1.4 \%$ & 2013 & 2.351 & 3 \\
\hline Journal of the Operational Research Society & 1 & $1.4 \%$ & 2011 & 2.175 & 3 \\
\hline Management Accounting Research & 4 & $5.6 \%$ & $2012-2015$ & 5.070 & 3 \\
\hline Production Planning and Control & 3 & $4.2 \%$ & $2013-2014$ & 3.605 & 3 \\
\hline Supply Chain Management: An International Journal & 4 & $5.6 \%$ & $2012-2014$ & 4.725 & 3 \\
\hline Third Area - General Management & 4 & $6 \%$ & $2008-2018$ & 19.325 & \\
\hline Abacus & 1 & $1.4 \%$ & 2009 & 2.480 & 3 \\
\hline International Journal of Human Resource Management & 1 & $1.4 \%$ & 2015 & 3.040 & 3 \\
\hline Journal of the Academy of Marketing Science & 1 & $1.4 \%$ & 2011 & 7.959 & 4 \\
\hline Technological Forecasting and Social Change & 1 & $1.4 \%$ & 2018 & 5.846 & 3 \\
\hline
\end{tabular}

"Journal of Cleaner Production" (29 papers), which has always been at the forefront of publishing sustainability and PM topics, followed by "Business Strategy and the Environment" (15), "Supply Chain Management: An International Journal", “Journal of Business Ethics" and "Management Accounting Research" (four papers for each journal). These journals highlighted the relevant role assumed by the sustainability issues in the PMS, and the growing interest in the last ten years by researchers and practitioners. Moreover, the distribution underscored that the topic analyzed is being used in various fields. Moreover, the high IF associated to the majority of the journals of the sample underline their relevance.

\subsection{Research methodology applied in the sample}

This type of analysis provided insights into the methodologies that have been made in the field of research (see Fig. 4).

By analyzing frequency distribution of the articles, it was evident that environmental dimensions were addressed using different methods and from different points of view. According to
Seuring and Müller (2008), we differentiated five research methodologies: (1) Theories; (2) Case studies; (3) Surveys; (4) Models; and (5) Literature Reviews. In Fig. 4, we observed that scholars focused mainly on the theoretical perspective (26) for addressing questions about the topic in order to analyze the interrelationships between sustainability and PMS analysis.

With regard to the quantitative approach, the model's methodology included twenty articles and the survey included three articles. The qualitative approach under the category Case Studies included fourteen articles and literature reviews included eight articles. In this context, the qualitative analysis is a relevant driver of the performance that reflects a subjective nature and properties of the value creation system, which cannot be directly obtained from the quantitative data (Parker, 2012). From the fourteen Case Studies, in two papers (Motevali Haghighi et al., 2016; Bai et al., 2012), a statistical method was used. Among the limited empirical cases, most experiences were from developed areas (e.g., UK, Australia, EU), and scattered cases were reported from developing countries, i.e. China, Brazil and India. 


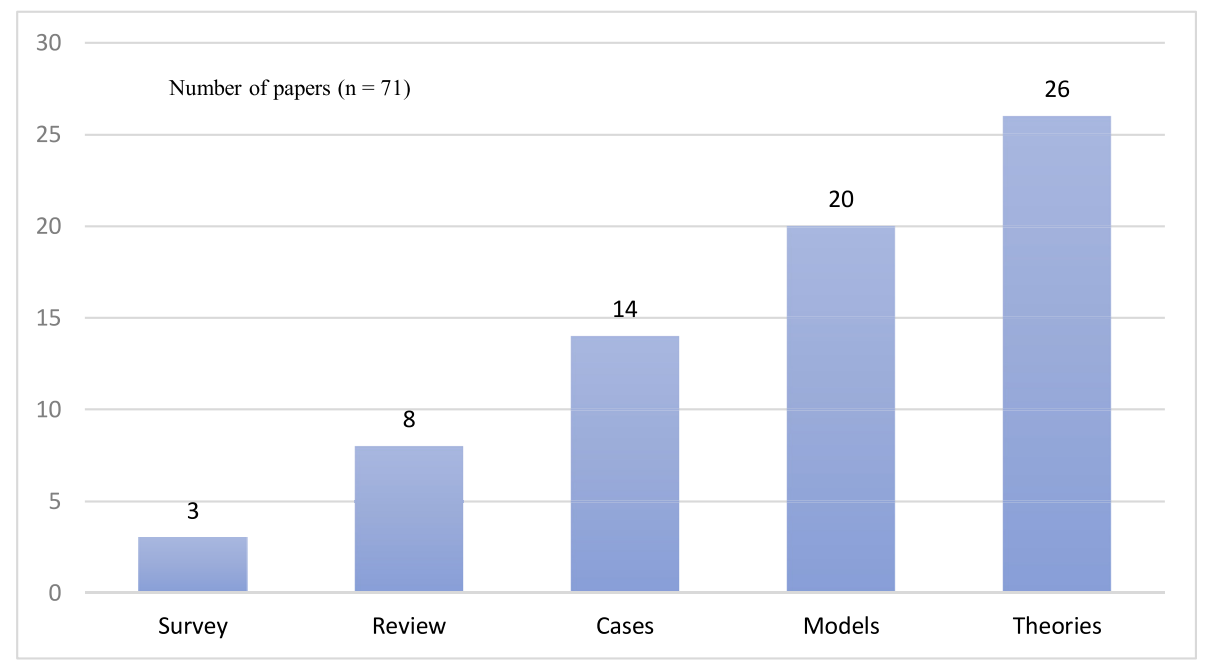

Fig. 4. Distribution by research methodology.

\section{Summary of content of the 71 selected articles}

After the descriptive review, we analyzed all 71 papers in the following subsections, by defining a classification synthesis to discuss and review the papers selected based on our first research question (Rq1). In particular, we identified four main key categories (see Table 3): 1) practices and measures, 2) impact on performance, 3) organizational drivers, and 4) critical issues and challenges, and discussed as follow.

\subsection{Practices and measures}

In this category, we included all issues that emerged, from the sample selected, in terms of measures and practices aimed to integrate the environment and the PMS (we conducted our analysis in this step based on the question: What were the main managerial practices used in trying to integrate the environmental dimension into the PMS?). A total of 49 papers addressed this crucial aspect in depth, by identifying different methodological models. The authors found that a large part of them were based on the creation and selection of an adequate KPI system for implementing and monitoring strategy oriented towards environmental performance. In the case studies, the selection of the KPIs required an accurate analysis of the goals, initiatives, processes and internal dynamics (Dagiliene et al., 2020; Pham et al., 2020; Haffar and Searcy, 2018; Schöggl et al., 2016).

For example, in recent years, particular attention was given to the corporate environmental responsibility model (CER) developed by He et al. (2017). In the same way, Bhattacharyya and Cummings (2015) reported a successful study of implementing the environmental performance measurement (EPM) model by developing a comprehensive set of KPIs. In this context, for each strategic goal related to the environmental dimension identified, it was necessary to define a specific set of indicators that allowed implementing strategy and monitoring the effectiveness of the strategic plan.

Accordingly, throughout the analyses of the selected papers, the authors documented that the most common environmental KPIs used in environmental management were in four categories: 1) emissions, 2) consumption of natural resources, 3) renewable resources, and 4) eco-efficiency. With regard to emissions, the KPIs were related to the pollution index (air, water, land), greenhouse gas emissions, ozone-depleting substances, fossil-carbon footprints, SOx emissions and NOx emissions (Trianni et al., 2019; Le Tellier et al., 2019; He et al., 2017).

Similarly, most KPIs were focused upon 'consumption of natural resources' connected to energy intensity levels, electricity consumption rates, soil use index and water consumption index (Motevali Haghighi et al., 2016; Bhattacharyya and Cummings, 2015). Moving to the dimension called 'renewable resources', the KPIs were focused on the waste reduction rates, reusable/recycled materials index, the biodiversity protection rate and the renewable electric sources index (Le Tellier et al., 2019; Rodrigues et al., 2016). Finally, the KPIs connected to eco-efficiency were related to the environmental costs, earnings, and savings (Virtanen et al., 2013).

These categories need to be integrated into the PMS based on a cause-effect alignment. Shahbazi et al. (2018) provided an interesting overview on the characteristics and required qualities of the environmental indicators. The authors identified elements such as comparability, measurability, conicity and universality. This approach allowed them to develop flexible indicators that were adequate to support the decision-making process. A study by Ahmadi et al. (2016) deeply discussed the importance of integrating alternative renewable resources into the strategy and the necessity to encapsulate them in the PMS. Another branch of research,

Table 3

Concepts described in the four key categories.

\begin{tabular}{|c|c|}
\hline Categories & Related concepts generated from the analysis \\
\hline practices and measures & $\begin{array}{l}\text { corporate environmental responsibility model (CER); environmental performance measurement (EPM); Balanced Scorecard (BSC); ISO standards } \\
\text { (ISO 9001, ISO 14001, ISO 26000, ISO 14031); Global Reporting Initiative (GRI); KPI system; }\end{array}$ \\
\hline impact on performance & $\begin{array}{l}\text { financial performance; investment opportunities; quality improvement; developing new markets; enhanced stakeholder trust; improved } \\
\text { organizational brand; environmental performance (emission, consumption, renewable resources and eco-efficiency); }\end{array}$ \\
\hline $\begin{array}{l}\text { organizational drivers } \\
\text { critical issues and } \\
\quad \text { challenges }\end{array}$ & $\begin{array}{l}\text { learning and growth process; cultural change; transparency; industry; geographic location; company's size; } \\
\text { selection of suitable KPIs; cultural transformation; isolating the value added from environmental initiatives; inter-connections among financial } \\
\text { benefits, short term results and the environmental dimensions. }\end{array}$ \\
\hline
\end{tabular}


pursue the integration, distinguishes between environmental managerial performance and environmental operational performance indicators (Bhattacharyya, 2019; Trumpp et al., 2013). In this approach, all indicators were addressed considering the organizational system, operational countermeasures, stakeholder relations and environmental tracking. Therefore, the KPI system is a useful means to link the environmental dimension to the PMS to help to enable companies to achieve sustainable values (Addison et al., 2020). The exploitation of these indicators emerged as a possible pillar for further sustainable evolution linked to development of new models and theoretical frameworks.

An important note is due to the BSC that was used to implement environmental management. To this end, traditional perspectives of the BSC were integrated with the environmental dimension as well. For example, Chalmeta and Palomero (2011) proposed defining a system of indicators based on the cause-and-effect relations by using the BSC approach. To this end, it was important to define a scorecard by integrating sustainable dimensions, goals and KPIs (Figge et al., 2002; Kim and Rhee, 2012; Hansen and Schaltegger, 2016, 2018; Xia et al., 2017; Nicoletti Junior et al., 2018).

Several other different tools were supported by the related literature based on multidimensional indicators, reporting and control, such as the GRI framework (Perrini and Tencati, 2006; Rodrigue et al., 2013; Varsei et al., 2014; Chiarini, 2017). In addition, the role played by the ISO standards (ISO 9001, ISO 14001, ISO 26000 , ISO 14031) was relevant, because they serve as the foundation and starting points for integration of these concepts and strategies into their daily processes (Cubas-Díaz and Martinez Sedano, 2017; de Villiers et al., 2016; Ahmadi et al., 2016; Campos et al., 2015). The findings revealed that in the last few years, an ever-growing number of companies are integrating environmental dimensions into their business models and implementation strategies.

\subsection{Impact on the performance}

This section summarizes the main benefits perceived by the integration process. From the sample analysis, it clearly emerged how the integration process is driven by the main motivation to improve the financial performance, indirectly connected to the environmental outcomes. Therefore, accounting income remains the core of the decision-making process. Moreover, this consideration does not necessarily contribute negatively to the company, but its excessive focus represents a barrier for managers and could lead to the failure of the process (Lee and Farzipoor Saen, 2012). More cultural change in the organization is required to see beyond the financial terms. In particular, environmental benefits have been empirically evaluated in terms of emissions, consumption and recycling, and their integration in the PMS indirectly impacts on the image, reputation, motivation, integration and cultural change of the company (Lisi, 2015; Acquaye et al., 2014; Seuring and Gold, 2013; Rodrigue et al., 2013).

Trianni et al. (2019) stated that a positive effect was documented of using an integrated framework to monitor the internal and external effects. To this end, from a theoretical point of view, authors developed an interesting discussion on the needs to adapt to a holistic approach based on the KPI system. A recent contribution by Bhattacharyya (2019), based on a survey in Australia, highlighted the inefficiencies due to the lack of or inappropriate integration of the environmental dimensions into a firm's operations. Authors of several papers highlighted possible competitive advantages related to better investment opportunities, quality improvement, developing new markets, enhanced stakeholder trust, improved organizational brand and better financial performance (Haffar and Searcy, 2018; Xia et al., 2017; Chen et al., 2017; Rodrigues et al.,
2016; Lisi, 2015; Guerci et al., 2016; Yin and Schmeidler, 2008; Adams and Frost, 2008).

Most of the empirical studies were implemented in manufacturing companies where the benefit was more visible in terms of natural resources' consumption (water, energy, soil, forest and land). For example, Shahbazi et al. (2018) provided empirical evidence on the role of recycling and its impacts on financial and environmental performance. Despite this positive impact, only a few countries and organizations provide specific regulations with regard to waste and materials' recycling. In the same way, the study conducted by Nicoletti Junior et al. (2018) in Brazil analyzed the integration in a manufacturing company using a BSC approach.

In addition, the analysis related to the role covered by ecoefficiency in sustainable development is relevant (Lee and $\mathrm{Wu}$, 2014; Bhattacharya et al., 2014; Virtanen et al., 2013). The consideration of eco-efficiency enabled companies to improve their performance by reducing costs due to better efficiency and productivity. The integration of all the dimensions analyzed led to improved decision making.

Despite several contributions that affirm a positive impact on company performance, authors of several papers highlighted the effects of minimal integration of strategic and operational levels, and an excessive attention on the financial results and the shortterm vision (Shahbazi et al., 2018; Dutta et al., 2013; Bai et al., 2012). In fact, the majority of the companies that implemented a sustainable strategy still remained focused on the economic pillar in the short-term, and this inhibited them from achieving full integration.

This analysis revealed that a significant proportion of the authors who analyzed company performance impacts, due to integrating environmental dimensions with PMS, did so in the last ten years, which underscored the recent and growing interest in this research field.

\subsection{Organizational drivers}

Analysis of the papers showed that achieving environmental integration depends on several organizational factors. Firstly, the company culture context plays an important relevant role in this process. A flexible and integrated context could impact positively on the introduction of a PMS-oriented environment (Shahbazi et al., 2018). For example, Bisbe and Malagueño (2012) pointed out how strategic alignment influences the performance of process integration. Therefore, a learning and growth process for each business unit is essential for preparing all members, from strategic to operational levels, to manage the change (Wu et al., 2018; Bonacchi and Rinaldi, 2007; Günther and Kaulich, 2005).

Machado et al. (2017) found that organizations tend to execute only what is mandatory. Accordingly, this criticism does not support full integration until the necessary cultural changes are made. This process involves several external and internal factors linked between them. In this scenario, transparency has an impact on the growing sensitivity of the local communities and, consequently, on stakeholder acceptance (Guerci et al., 2016). The geographic location was also an important driver, with regard to local environmental legislation and regulations, where incentives and investment opportunities were or were not provided. The countriesin the selected articles included Australia, Brazil, Canada, China, Germany, Iran, Italy, Korea, Sweden and the UK. In addition, contextual drivers depend on the company's size and sector where the environmental PMS is implemented. Several case studies focused on the suitable results obtained in the manufacturing sector (Nicoletti Junior et al., 2018; He et al., 2017; Azevedo et al., 2012). Shahbazi et al. (2018) proposed an integrated approach based upon empirical evidence, from Italian and German 
manufacturing companies, on the successes of the integration process in this sector. This was due to the specific characteristics of the manufacturing companies, where employees were confident with the environmental issues, and the cultural change was strengthened. Many authors emphasized the positive results obtained by implementing sustainable systems in small and medium enterprises (SMEs), where the distance between the strategic and the operational levels is small (Trianni et al., 2019; Günther and Kaulich, 2005).

The role of the actors involved is crucial in this process. In particular, internal drivers, such as moral obligation, motivation, long-term orientation, leadership and management commitment, are required to support the integration process and accelerate its acceptance (Sroufe, 2017; Lisi, 2015). Given the complexity of the integrated approach, a structured process based on the interconnection of several organizational drivers is required.

\subsection{Critical issues and challenges}

In the last 20 years, the consideration of the environmental dimensions in the PMS represented a hard challenge for companies. Despite previous efforts (Burritt, 2004; Dey and Cheffi, 2013; Genovese et al., 2014; Guerci et al., 2016), this integration process still remains a major challenge for decision makers. In particular, several issues emerged from the literature analysis.

Firstly, difficulties have persisted in the selection of suitable KPIs to be used to monitor and implement the environmental PMS (Shahbazi et al., 2018). Much attention was given to the external perspectives, based on the stakeholders needs (Trianni et al., 2019), without adequately considering the internal decision-making processes (Bai and Sarkis, 2014). Environmental dimensions must be clearly identified and included in a common structured framework, by connecting each of them to the specific strategic goals and to the KPIs (Garcia et al., 2016).

In addition, one of the major criticalities was linked to the interconnection between the organization's members and their environmental cultures. Environmental dimensions are strictly connected to the human behavior, which define future orientation of a company and sustainable development (Le Tellier et al., 2019; de Villiers et al., 2016). Accordingly, a lack of transparency negatively impacts on the integration process (Venturelli et al., 2017). Therefore, people sensitive to the environmental dimensions could drive the cultural transformation by implementing the environment-oriented PMS.

Furthermore, assessing environmental performance by isolating the value added from environmental initiatives along the SCM requires deeper analysis (George et al., 2016; Schöggl et al., 2016).

A challenge that is still urgent for academics and practitioners is to define the inter-connections among financial benefits, short term results and the environmental dimensions (Hansen and Schaltegger, 2018). These relationships play fundamental roles in the integration process by stimulating managers in adopting a sustainable strategy. Resolving these trade-offs remains the key challenge (Wu et al., 2018). Therefore, a significant change is needed for implementing the environmental PMS. This change is based on structural transformation of the PMS implemented in the company, based on the definition of an environmental strategy and connected KPIs (Wu et al., 2018; Seele, 2016; Dutta et al., 2013; Xie and Hayase, 2007; Schneider and Meins, 2012).

\section{Content analysis}

The content analysis results are presented in a concept map (Fig. 5) and the relationships between "Performance" and related concepts are based on conditional probability. The concept map displays dots giving the names of concepts that have been identified from the texts. The size of the dot describes the frequency of that concept; the larger the dot, the more it has appeared in the dataset. The concepts on this map are located according to their comparative relevance. The most frequent connections (i.e., the cooccurrences) are indicated by the lines between the concept circles, although other interconnections might also exist. The network of pathways may represent the most likely relationships of concepts in the database.

\subsection{The general research trend}

In this section, the authors start with a descriptive discussion of the layout of the concept map and then try to investigate the possible implication of the map.

Evidently, "performance" is the prominent concept on this map; it is closely related to "measure" and "management". "Environmental" appears to be the dominant concept in the dataset and is surrounded by related concepts. These related concepts can be further divided into four categories: "emissions", consumption (e.g., "water", "electricity"), "resources" and "efficiency", which are the most common environmental dimensions used in environmental management. However, most of the environmental concepts are connected to "companies". On the one hand, this revealed that PMS-related tools (KPIs, GSC, ${ }^{1}$ etc.) are not key concepts for describing the environmental theme. On the other hand, this result confirms that previous researchers were aware of the importance of environmental dimensions for companies, but there have been few investigations on the integration of green dimensions into PMS evaluation strategies.

The second strongest link revealed that "measure" is more closely connected to "sustainability"; and "management" is more directly connected to "social" and "economic" concepts, which are two principles of the three pillars of sustainability. Clearly, the environmental aspects of sustainability in PMS papers were more likely to be focused at the management levels and less connected to the "performance measures", e.g., "KPIs" and "GRI".

As a matter of fact, the PMS process related that the concept "Decision-making" and measures related to concepts ("strategic environmental models", etc.) were more likely to be connected with sustainability concepts, not clearly showing its connection with environmental concepts.

Another critical concept is "value", which is not strongly connected to "performance", but is more closely linked with sustainability. This indicates that the value created related with sustainability was addressed in the dataset.

As shown in Fig. 5, the environmental issues emerged from the PMS research analysis at the beginning of the 21 st century. Then, the research focus turned to sustainable performance management, which includes all social, environmental and economic aspects. The Corporate Environmental Performance (CEP) became the most frequently discussed concept in the period from 2014 to 2020. On the other hand, this last period has a direct connection to PMS "indicators", which suggests that research was done to investigate and evaluate the "greenness" of corporate performance and how to employ indicators to achieve the related objectives. Nevertheless, the dispersion of "indicator" and environmentally-related concepts suggests that integrating the environmental dimensions into PMS is a research gap. Indeed, more research is needed to identify how to combine environmental dimensions into performance indicators and management systems.

\footnotetext{
${ }^{1}$ Green Supply Chain.
} 


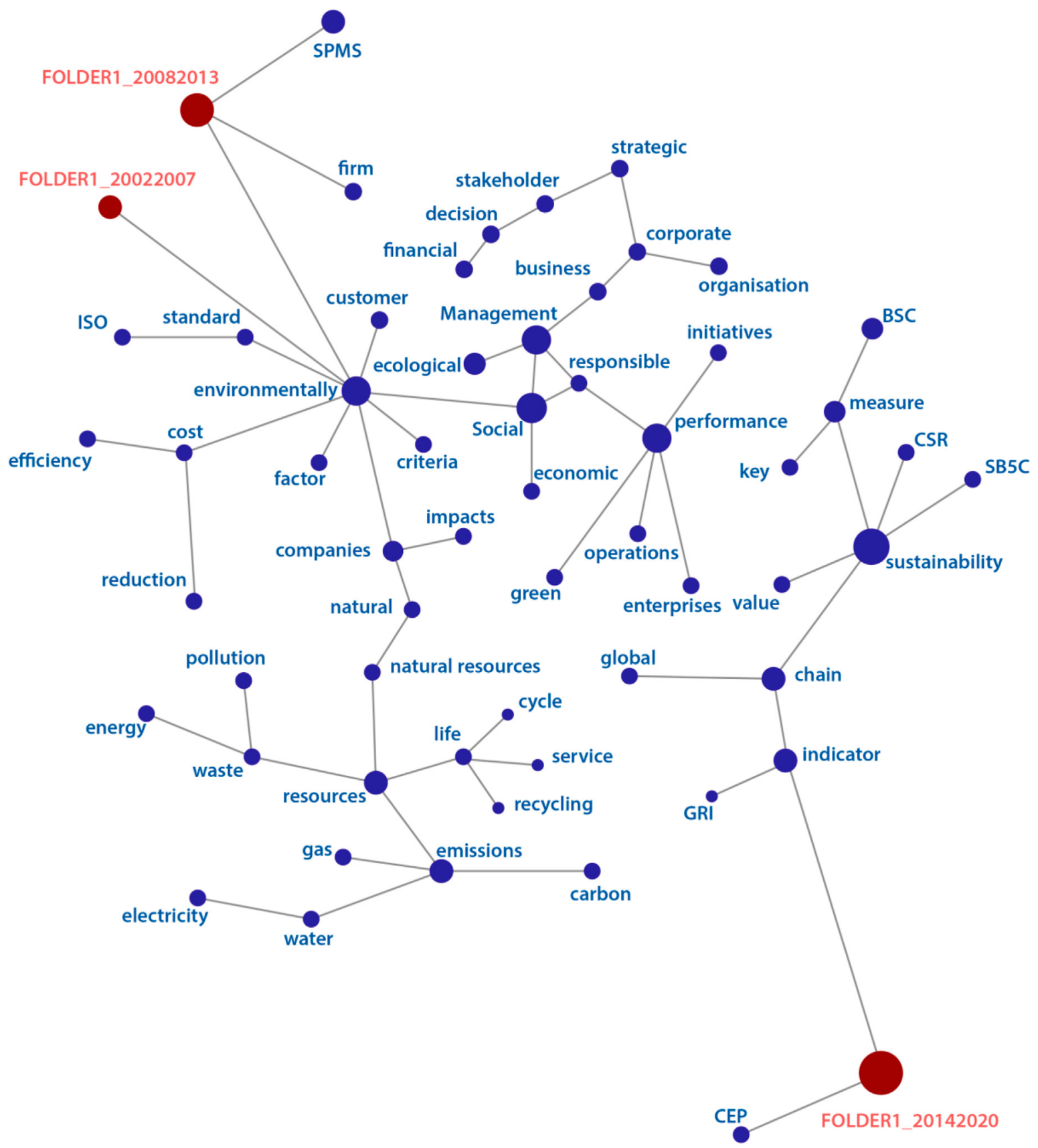

Fig. 5. Content Map extracted based on selected literature from 2002 to 2020.

\subsection{The evolution of PMS research}

In this section, the authors explore the evolution of PMS research during the last 20 years. The dataset was divided into three phases ${ }^{2}$ and the authors analyzed the dataset from two perspectives.

First, the authors review the most discussed concepts that evolved in last decade. The findings are presented in Fig. 6. Depicted as a Dashboard quadrant, it shows the most discussed concepts in the three phases. As defined in the Leximancer (2018) manual, the

\footnotetext{
2 The authors divided all the papers into three periods: 2002-2007, 2008-2013, 2014-2020, every 5 years as a period.
}

Frequency axis on the Quadrant graphic represents a conditional probability and it measures frequency of mention in the data. The Strength score is the reciprocal conditional probability, where strong concepts distinguish the Category from others, whether or not the Attribute is mentioned frequently (Fig. 7).

Due to the number of articles increasing during the period 2002-2020, the set of concepts of the last period is the one that appeared most frequently on the dashboard. The concept "Environmentally" is always the research focus of our dataset. However, considering the concepts on the Frequency score axis, the occurrence of "environmental" is less than $35 \%$, which indicates that the environmental aspect is still not adequately discussed in the PMS dataset. Isolating the concepts that emerged within each period, distinct research foci are revealed in different time periods. We 


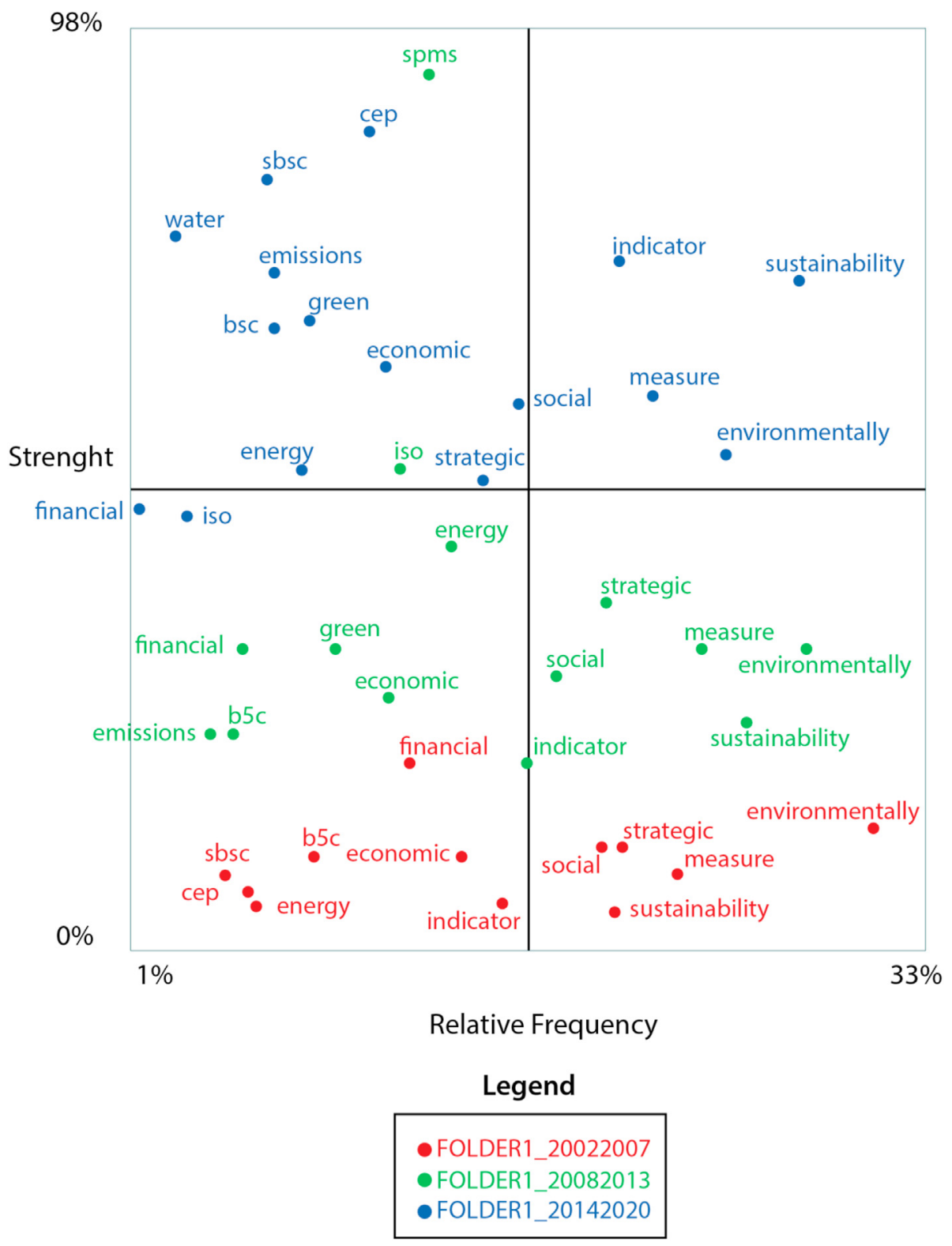

Fig. 6. Evolution of most discussed concepts over time.

have documented that environmentally-related concepts were dominant in the period from 2014 to 2020 . This change may be due to the fact that the research direction turned from "sustainability" to "environment", as sustainability-related concepts, i.e., "social" and "economic" were more likely to be discussed from 2002 to 2013. Meanwhile, the concept "financial" received less and less attention during the entire period covered by this review. It is also noteworthy that the "strategic" concept has been also consistently and frequently discussed throughout all three periods.

Next, the authors attempted to investigate the concepts' evolution with respect to the "performance" concept. The concepts fall mainly in two groups: one relates to the environment and the other to measurement. The result showed that environmental-related concepts, e.g., "recycling", "emissions", "water" and "resources", were emerging. At the same time, the discussion on the nonenvironmental part of the 17 UN SDGs decreased. However, measures and indicators were not particularly or strongly discussed in the context of performance, even though they received increased attention. Besides, "financial" and "management" are discussed less and less, as with "performance". The only concept that disappeared was "ecological". The reason may be due to the early stage of research, when sustainable performance was mentioned, and ecological performance was used to refer to environmental performance. Along with the consensus that was gradually built on the three pillars of sustainability (Purvis et al., 2019), "ecological" has been replaced by "environmental".

The results of our analysis suggest that the environmental issue was emerging in PMS research, however, the design of the PMS and relevant instruments were not deeply addressed with the environmental challenges, together with the evolving climate related impacts. Our results confirm that when company strategies are investigated, there is a lack of research that considers the integration of the environmental principle within PMS instruments.

\section{Theoretical development}

Based upon the analyses presented in previous sections, the authors developed a theoretical model (Fig. 8), which is an 


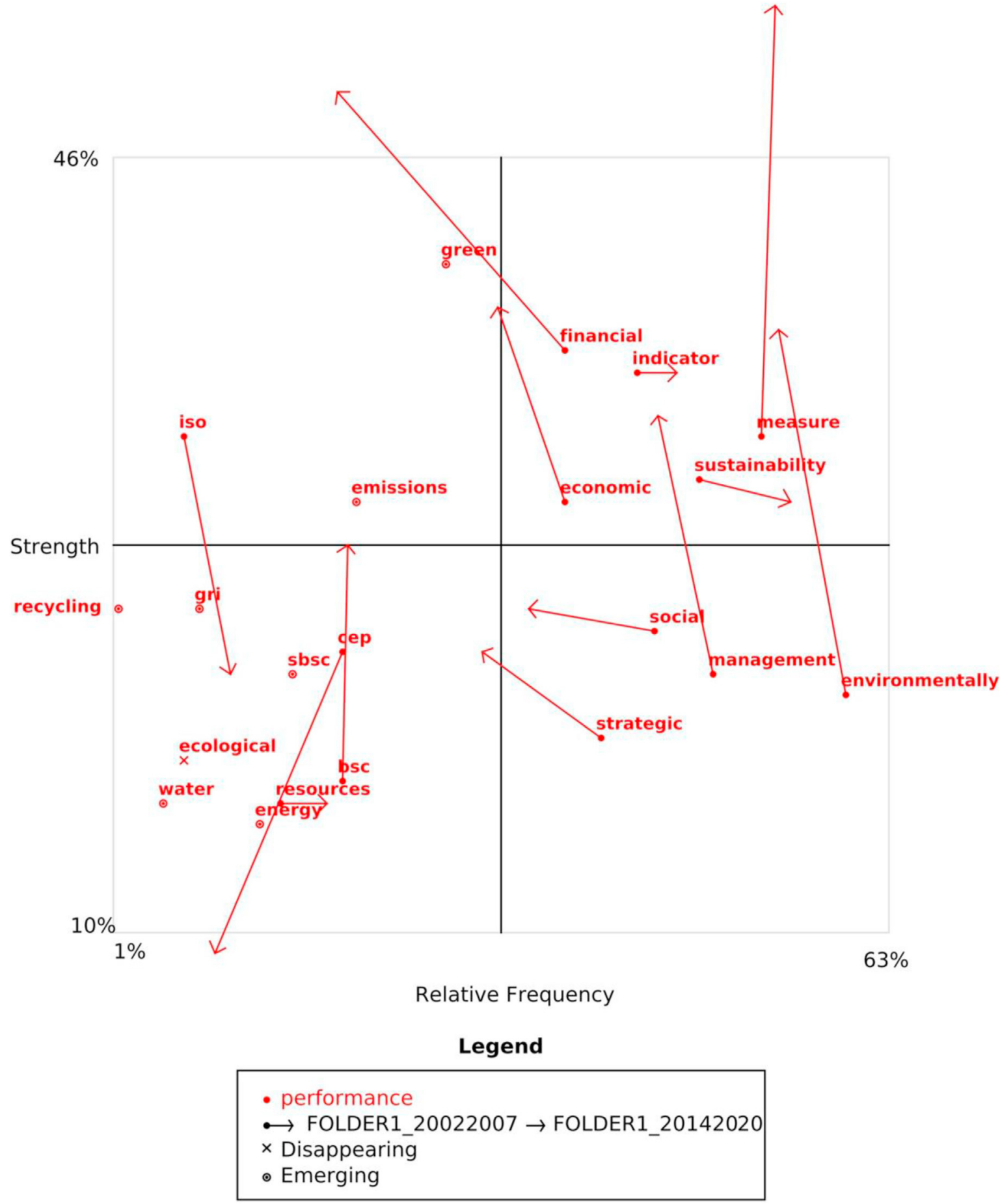

Fig. 7. Concepts discussed with respect to "Performance" over time.

extension of Fig. 1 and designed to provide a way to structure a sustainable approach to integrate environmental dimensions into the PMS (Rq2). In particular, it highlights the fundamental role of environmental perspectives in the PMS. Accordingly, the framework, called the environmental performance model (EPM), integrates all environmental dimensions identified in the literature, which need to be considered in the strategic plan. The alignment to the strategy is addressed by including the strategic environmental goals in the first step of the PMS cycle: "define and plan process". In particular, it is necessary to develop a sustainability plan, including strategic goals in terms of environmental dimensions that positively affect the companies' performance. Based on the literature review and content analysis results, we suggested four key dimensions (emissions, consumption, renewable energy and ecoefficiency) that were identified in the literature, which are directly correlated with sustainable development. Their inclusion, in the early stages of the PMS cycle, could help company decision makers to effectively integrate environmental dimensions into their PMSs. That would positively improve the sustainable value creation in terms of financial performance, environmental value, 


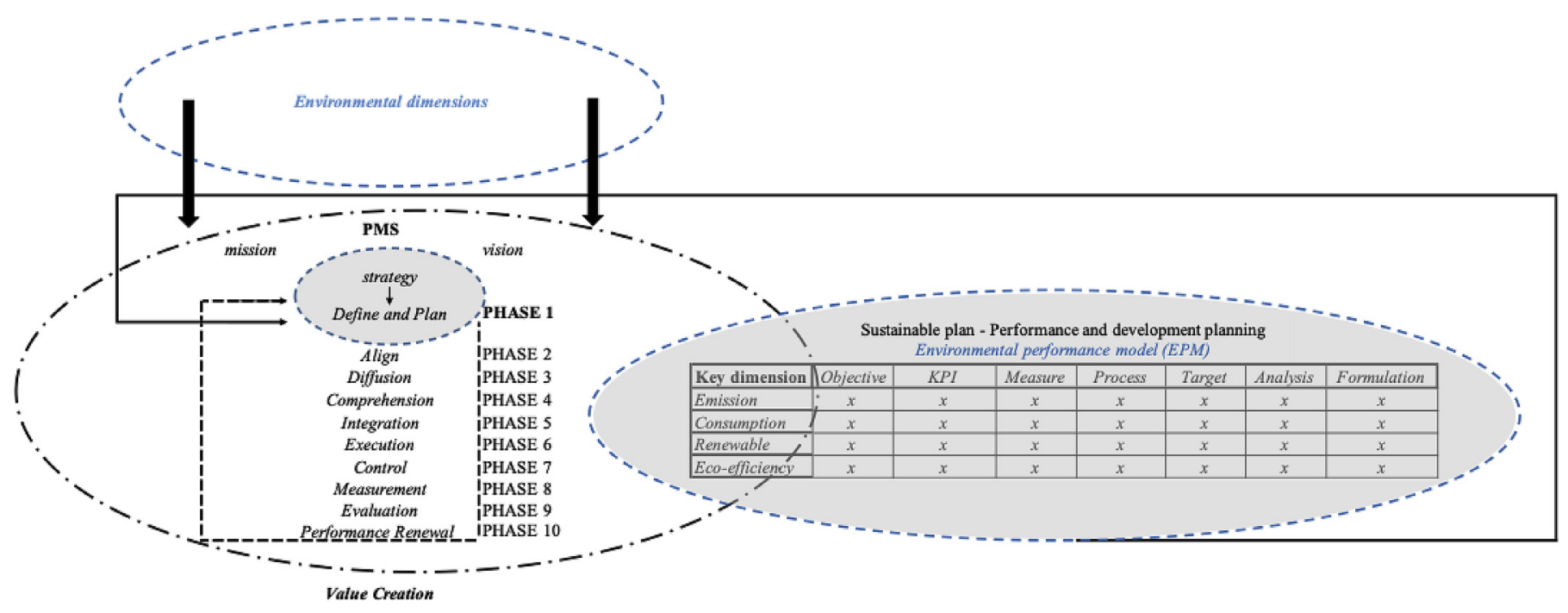

Fig. 8. Environmental performance model (EPM).

stakeholders' relationships (corporate image and reputation), and would have relevant cultural implications related to employees' motivation (internal) and to the environmental context (external). In defining goals and indicators, the strategic coherence among these elements assumes greater importance.

Therefore, it is necessary to move the first level shown by Fig. 1 (environmental dimension) to inside the third level (PMS cycle) in the early stage of the process (phase 1 ), connected to strategy development and planning. This integration will support effective facilitation of the information flow to all other PMS' phases. In particular, the alignment, diffusion and comprehension play central roles in preparing the organizational culture to realize the environmental changes and the integration (phase 5). Training hours, internal meetings, participation in events and initiatives could be properly planned to help to catalyze a more efficient and rapid change. Once the integration is completed, the organization will be ready to translate the new strategy adopted into action within the execution (phase 6) in order to achieve their environmental performance goals.

At this stage, the executive and operational approaches start, which require proper leadership and visionary controls, effective and consistent measurement and evaluation based on an appropriate set of KPIs that monitor the dimensions related to implementation and analysis. All processes, trends and challenges or problems must be regularly and consistently analyzed and interpreted to guide and update the PMS cycle and to improve the strategy and processes to implement them.

The authors identified four main key perspectives related to emissions, consumption, renewable resources and eco-efficiency that need to be rigorously implemented and monitored during the early stage of the PMS cycle.

For each of the perspectives shown in Fig. 8, a sustainability plan must be prepared in relation to the strategic goals, and the KPIs, under the categories: measure, process, target, analysis and formulation.

This approach should be designed to support decision makers in integrating all environmental dimensions and translating the strategic objectives of the organization into a set of integrated measures that enhance the company's sustainable value creation.

\section{Discussion and conclusions}

In this study, the authors conducted a comprehensive literature review of articles published between 2002 and 2020 pertaining to the evolving roles of environmental dimensions in a company's PMS. In this context, the authors contributed to the research field by addressing two specific research questions aimed at improving current knowledge about the environmental drivers and challenges of the integration process between environmental dimensions and the PMS. The authors added an additional step to the knowledge and understanding of the research field, as discussed in the following subsections.

\subsection{Theoretical and practical implications}

Considering the first research question (Rq1), a clear vision on the main environmental drivers has been added to the existing knowledge. By conducting the SLR and content analysis, the authors documented that, in the last eighteen years, interest in the topic has increased and achieved maximum interest in the last decade. The authors confirmed that environmental awareness was a common issue among different economic sectors (Farias et al., 2019) and was extremely important for measuring organizational performance. The results of our analyses documented that the majority of the researchers focused upon specific environmental dimensions connected to emissions, consumption, renewable resources and eco-efficiency. This contributed to the literature by clearly delineating the main performance outcomes, which still need to be studied, mostly from a management accounting perspective. The practical contribution of the study proved even more relevant. Our results have provided managers with a clear outline of practices and measures, performance outcomes, organizational drivers and critical issues linked to the environmental integration in the PMS. This is important because, as discussed in the introduction, this clarity can help to support the decisionmaking processes in the context of sustainable development.

With regard to our second research question (Rq2), the integration of environmental dimensions and the PMS underscored the urgent need for a clearer conceptual business model to face the changing and challenging contexts under which companies and governments are operating. The main challenge in the existing literature was to achieve the strategic alignment between the environment and the PMS. Therefore, managers will have to change their business models and strategic choices in the context of changing demands from governmental and other societal stakeholders. 
To this end, efforts were made by the authors of this literature review to investigate ways to integrate all environmental issues into the implementation process of the PMS, by using a particular set of indicators that can be used to help companies to focus on reducing emissions and natural resources' consumption, improving eco-efficiency, transitioning to renewable energy and engaging stakeholders at all levels of on-going dialogues.

The findings of this literature review were used to construct the Environmental Performance Model, which can be used to help company leaders to integrate and translate the environmental dimensions and strategic objectives of the organization into a set of measures leading to a clearer and more effective achievement of improved and sustainable value creation.

The model can be useful for managers who deal with sustainable issues at the strategic level, by implementing the framework as a strategic management tool to support decision-making processes, with relevant implications for practices. In addition, the theoretical development paves the way for future research, which will continue to explore ways of broadening and deepening the integration of all three pillars of sustainable development into more sustainable company performance.

The literature review and conceptual framework developed an integrated overview of criteria and practices that can be used to assess sustainability and performance and their impacts on organizational performance.

\subsection{Missing concepts and future directions}

A much more effective integration of the PMS and environmental dimensions is urgently needed, based on the authors' comprehensive analysis of environmental performance tracking and measurement in terms of sustainably managing natural resources, creating jobs, maintaining competitiveness, reducing dependence on non-renewable resources, mitigating and adapting to climate changes, including reducing energy demand and lowering emissions. This research gap was identified from the content analysis results.

By conducting the systematic review, the authors found that few empirical studies have been done, and that the research topics and locations were limited. The authors found that the number of articles, as published in the field analyzed, increased in recent years, but the areas covered were not thoroughly investigated. Most of the articles focused on the manufacturing industry. In the future, more studies should explore applications in other sectors, such as healthcare, food, finance and construction, and should include not only private, but also public sector companies. Currently, there are only a few studies on the integration of environmental dimensions and PMS in Public Administrations that aimed to improve their sustainability performance. Additionally, to improve the breadth of research on this topic, it is urgent that comparative analyses are performed across different countries using the multiple case study methodology (Cheng et al., 2018).

In the selected articles, the authors found several that addressed theory and modeling as their methodological approaches, but only a few reviews and surveys were published. Concerning case studies, it will be important to use this approach to plan and systematically perform multiple semi-structured interviews, which are necessary to analyze the results and to better identify the main issues that require more in-depth research.

For future research, our findings underscored the trends and needs for improving the sustainability performance of a company's PMSs. More scholars and practitioners should co-work, using a diversity of old and new theories and practices. This will help the scientific community, industrialists, governmental policy makers and NGOs to co-work to experiment with new ways to help the transition to truly sustainable, equitable, livable societies.

The findings of this review underscored the roles played by cultural changes and organizational structures in terms of growth, dialogue and participation of individuals and communities. Becoming aware that sustainability integration is inevitably a cultural factor is important as we seek to work locally, regionally, nationally and globally.

The goals and related indicators require a high-level degree of cultural change and experiences within diverse types of organizations. Cultural determinants have become essential to create a strong foundation for efficient, effective and rapid implementation of sustainability into all levels of business and government. For sure, cultural changes in organizations are required to more adequately integrate the environmental, social and economic dimensions of companies for the short and long-term future. In doing so, they can become integral to the urgently needed changes that must be made regarding human population growth, climate change that continues to increase far beyond what was agreed by leaders of nearly all countries in the 2015 Paris Agreement on Climate Change, and the present and future impacts of the COVID-19 pandemic and of similar future pandemics. It is urgent that holistic, integrative, multi-disciplinary research should be supported and performed to address these gigantic problems, which are integral to fulfilling the UN's 17 Sustainable Development Goals.

\subsection{Limitations of the research}

This paper has a limitation linked to the broadness of the review. More specifically, given the setting adopted by the authors, to focus on the contributions of the heterogeneous set of journals and sources, the authors highlighted general avenues where additional work is needed. The authors are convinced that this is an important first step for future research, but will leave the assessment of the "field specific" links to future, more narrowly-focused research efforts.

Finally, the research design of this study, as previously discussed, may constitute a further opportunity to improve the obtained results. Eventually, the relationships among topics reported in the model might be subject to large-scale generalizations to improve the level of the evidence on this topic and to promote more, pro-active, holistic practices at corporate, governmental, academic and NGO levels.

\section{Declaration of competing interest}

The authors declare that they have no known competing financial interests or personal relationships that could have appeared to influence the work reported in this paper.

\section{References}

Acquaye, A., Genovese, A., Barrett, J., Lenny Koh, S.C., 2014. Benchmarking carbon emissions performance in supply chains. Supply Chain Manag. 19, 306-321. https://doi.org/10.1108/SCM-11-2013-0419.

Adams, C.A., Frost, G.R., 2008. Integrating sustainability reporting into management practices. Account. Forum 32, 288-302. https://doi.org/10.1016/ j.accfor.2008.05.002.

Addison, P.F., Stephenson, P.J., Bull, J.W., Carbone, G., Burgman, M., Burgass, M.J., Reuter, K.E., 2020. Bringing sustainability to life: a framework to guide biodiversity indicator development for business performance management. Bus. Strat. Environ. 29 (8), 3303-3313.

Ahmadi, A., Tiruta-Barna, L., Benetto, E., Capitanescu, F., Marvuglia, A., 2016. On the importance of integrating alternative renewable energy resources and their life cycle networks in the eco-design of conventional drinking water plants. J. Clean. Prod. 135, 872-883. https://doi.org/10.1016/j.jclepro.2016.06.201.

Azevedo, S.G., Carvalho, H., Duarte, S., Cruz-Machado, V., 2012. Influence of green and lean upstream supply chain management practices on business sustainability. IEEE Trans. Eng. Manag. 59, 753-765. https://doi.org/10.1109/ TEM.2012.2189108. 
Bai, C., Sarkis, J., 2014. Determining and applying sustainable supplier key performance indicators. Supply Chain Manag. 19, 275-291. https://doi.org/10.1108/ SCM-12-2013-0441.

Bai, C., Sarkis, J., Wei, X., Koh, L., 2012. Evaluating ecological sustainable performance measures for supply chain management. Supply Chain Manag. 17, 78-92. https://doi.org/10.1108/13598541211212221.

Bhattacharyya, A., 2019. Corporate environmental performance evaluation: a crosscountry appraisal. J. Clean. Prod. 237, 117607. https://doi.org/10.1016/ j.jclepro.2019.117607.

Bhattacharyya, A., Cummings, L., 2015. Measuring corporate environmental performance - stakeholder engagement evaluation. Bus. Strat. Environ. 24, 309-325. https://doi.org/10.1002/bse.1819.

Bhattacharya, A., Mohapatra, P., Kumar, V., Dey, P.K., Brady, M., Tiwari, M.K., Nudurupati, S.S., 2014. Green supply chain performance measurement using fuzzy ANP-based balanced scorecard: a collaborative decision-making approach. Prod. Plann. Contr. 25, 698-714. https://doi.org/10.1080/ 09537287.2013.798088.

Bisbe, J., Malagueño, R., 2012. Using strategic performance measurement systems for strategy formulation: does it work in dynamic environments? Manag. Account. Res. 23, 296-311. https://doi.org/10.1016/j.mar.2012.05.002.

Bonacchi, M., Rinaldi, L., 2007. Dartboards and clovers as new tools in sustainability planning and control. Bus. Strat. Environ. 16, 461-473. https://doi.org/10.1002/ bse. 596.

Burritt, R.L., 2004. Environmental management accounting: roadblocks on the way to the green and pleasant land. Bus. Strat. Environ. 13, 13-32. https://doi.org/ $10.1002 /$ bse.379.

Campos, L.M.S., De Melo Heizen, D.A., Verdinelli, M.A., Cauchick Miguel, P.A., 2015. Environmental performance indicators: a study on ISO 14001 certified companies. J. Clean. Prod. 99, 286-296. https://doi.org/10.1016/ j.jclepro.2015.03.019.

Chalmeta, R., Palomero, S., 2011. Methodological proposal for business sustainability management by means of the Balanced Scorecard. J. Oper. Res. Soc. 62, 1344-1356. https://doi.org/10.1057/jors.2010.69.

Chen, C.S., Yu, C.C., Hu, J.S., 2017. Constructing performance measurement indicators to suggested corporate environmental responsibility framework. Technol. Forecast. Soc. Change 135, 33-43. https://doi.org/10.1016/ j.techfore.2017.05.033.

Chiarini, A., 2017. Environmental policies for evaluating suppliers' performance based on GRI indicators. Bus. Strat. Environ. 26, 98-111. https://doi.org/10.1002/ bse.1907.

Crittenden, V.L., Crittenden, W.F., Ferrell, L.K., Ferrell, O.C., Pinney, C.C., 2011. Market-oriented sustainability: a conceptual framework and propositions. J. Acad. Market. Sci. 39, 71-85. https://doi.org/10.1007/s11747-010-0217-2.

Cubas-Díaz, M., Martínez Sedano, M., 2017. Measures for sustainable investment decisions and business strategy - a triple bottom line approach. Bus. Strat. Environ. https://doi.org/10.1002/bse.1980.

Dagiliene, L., Frendzel, M., Sutiene, K., Wnuk-Pel, T., 2020. Wise managers think about circular economy, wiser report and analyze it. Research of environmental reporting practices in EU manufacturing companies. J. Clean. Prod. 274, 121968.

de Villiers, C., Rouse, P., Kerr, J., 2016. A new conceptual model of influences driving sustainability based on case evidence of the integration of corporate sustainability management control and reporting. J. Clean. Prod. 136, 78-85. https:// doi.org/10.1016/j.jclepro.2016.01.107.

Dey, P.K., Cheffi, W., 2013. Green supply chain performance measurement using the analytic hierarchy process: a comparative analysis of manufacturing organisations. Prod. Plann. Contr. 24, 702-720. https://doi.org/10.1080/ 09537287.2012.666859.

Dutta, S.K., Lawson, R.A., Marcinko, D.J., 2013. Alignment of performance measurement to sustainability objectives: a variance-based framework. J. Account. Publ. Pol. 32, 456-474. https://doi.org/10.1016/j.jaccpubpol.2013.08.008.

Figge, F., Hahn, T., Schaltegger, S., Wagner, M., 2002. The sustainability balanced scorecard. Linking sustainability management to business strategy. Bus. Strat. Environ. 284, 269-284.

Garcia, S., Cintra, Y., de Cássia, S.R., Torres, R., Lima, F.G., 2016. Corporate sustainability management: a proposed multi-criteria model to support balanced decision-making. J. Clean. Prod. 136, 181-196. https://doi.org/10.1016/ j.jclepro.2016.01.110.

Genovese, A., Lenny Koh, S.C., Kumar, N., Tripathi, P.K., 2014. Exploring the challenges in implementing supplier environmental performance measurement models: a case study. Prod. Plann. Contr. 25, 1198-1211. https://doi.org/10.1080/ 09537287.2013.808839.

Genovese, A., Morris, J., Piccolo, C., Koh, S.C.L., 2017. Assessing redundancies in environmental performance measures for supply chains. J. Clean. Prod. 167, 1290-1302. https://doi.org/10.1016/j.jclepro.2017.05.186.

George, R.A., Siti-Nabiha, A.K., Jalaludin, D., Abdalla, Y.A., 2016. Barriers to and enablers of sustainability integration in the performance management systems of an oil and gas company. J. Clean. Prod. 136, 197-212. https://doi.org/10.1016/ j.jclepro.2016.01.097.

Guerci, M., Longoni, A., Luzzini, D., 2016. Translating stakeholder pressures into environmental performance - the mediating role of green HRM practices. Int. J. Hum. Resour. Manag. 27, 262-289. https://doi.org/10.1080/ 09585192.2015.1065431.

Günther, E., Kaulich, S., 2005. The EPM-KOMPAS: an instrument to control the environmental performance in small and medium-sized enterprises (SMEs). Bus. Strat. Environ. 14 (6), 361-371. https://doi.org/10.1002/bse.437.
Haffar, M., Searcy, C., 2018. The use of context-based environmental indicators in corporate reporting. J. Clean. Prod. 192, 496-513. https://doi.org/10.1016/ j.jclepro.2018.04.202.

Hansen, E.G., Schaltegger, S., 2016. The sustainability balanced scorecard: a systematic review of architectures. J. Bus. Ethics 133, 193-221. https://doi.org/ 10.1007/s10551-014-2340-3.

Hansen, E.G., Schaltegger, S., 2018. Sustainability balanced scorecards and their architectures: irrelevant or misunderstood? J. Bus. Ethics 150, 937-952. https:// doi.org/10.1007/s10551-017-3531-5.

Hassini, E., Surti, C., Searcy, C., 2012. A literature review and a case study of sustainable supply chains with a focus on metrics. Int. J. Prod. Econ. 140, 69-82. https://doi.org/10.1016/j.ijpe.2012.01.042.

He, Z., Chen, P., Liu, H., Guo, Z., 2017. Performance measurement system and strategies for developing Low-carbon logistics: a case study in China. J. Clean. Prod. 156, 395-405. https://doi.org/10.1016/j.jclepro.2017.04.071.

Hubbard, G., 2009. Measuring organizational performance: beyond the triple bottom line. Bus. Strat. Environ. 18, 177-191. https://doi.org/10.1002/bse.564.

Kim, J., Rhee, J., 2012. An empirical study on the impact of critical success factors on the balanced scorecard performance in Korean Green supply chain management enterprises. Int. J. Prod. Res. 50, 2465-2483. https://doi.org/10.1080/ 00207543.2011.581009.

Le Tellier, M., Berrah, L., Stutz, B., Audy, J.F., Barnabé, S., 2019. Towards sustainable business parks: a literature review and a systemic model. J. Clean. Prod. 216, 129-138. https://doi.org/10.1016/j.jclepro.2019.01.145.

Lee, K.H., Farzipoor Saen, R., 2012. Measuring corporate sustainability management: a data envelopment analysis approach. Int. J. Prod. Econ. 140, 219-226. https:// doi.org/10.1016/j.ijpe.2011.08.024.

Lee, K.H., Wu, Y., 2014. Integrating sustainability performance measurement into logistics and supply networks: a multi-methodological approach. Br. Account. Rev. 46, 361-378. https://doi.org/10.1016/j.bar.2014.10.005.

Lisi, I.E., 2015. Translating environmental motivations into performance: the role of environmental performance measurement systems. Manag. Account. Res. 29, 27-44. https://doi.org/10.1016/j.mar.2015.06.001.

Maas, K., Schaltegger, S., Crutzen, N., 2016. Advancing the integration of corporate sustainability measurement, management and reporting. J. Clean. Prod. 133, 859-862.

Maas, S., Reniers, G., 2014. Development of a CSR model for practice: connecting five inherent areas of sustainable business. J. Clean. Prod. 64, 104-114. https:// doi.org/10.1016/j.jclepro.2013.07.039.

Machado, C.G., de Lima, E.P., da Costa, S.E.G., Angelis, J.J., Mattioda, R.A., 2017. Framing maturity based on sustainable operations management principles. Int J. Prod. Econ. 190, 3-21. https://doi.org/10.1016/j.ijpe.2017.01.020.

Morioka, S.N., de Carvalho, M.M., 2016. A systematic literature review towards a conceptual framework for integrating sustainability performance into business. J. Clean. Prod. 136, 134-146. https://doi.org/10.1016/j.jclepro.2016.01.104.

Motevali Haghighi, S., Torabi, S.A., Ghasemi, R., 2016. An integrated approach for performance evaluation in sustainable supply chain networks (with a case study). J. Clean. Prod. 137, 579-597. https://doi.org/10.1016/ j.jclepro.2016.07.119.

Nawrocka, D., Parker, T., 2009. Finding the connection: environmental management systems and environmental performance. J. Clean. Prod. 17, 601-607. https:// doi.org/10.1016/j.jclepro.2008.10.003.

Nicoletti Junior, A., de Oliveira, M.C., Helleno, A.L., 2018. Sustainability evaluation model for manufacturing systems based on the correlation between triple bottom line dimensions and balanced scorecard perspectives. J. Clean. Prod. 190, 84-93. https://doi.org/10.1016/j.jclepro.2018.04.136.

Perego, P., Hartmann, F., 2009. Aligning performance measurement systems with strategy: the case of environmental strategy. Abacus 45, 397-428. https:// doi.org/10.1111/j.1467-6281.2009.00297.x.

Perrini, F., Tencati, A., 2006. Sustainability and stakeholder management: the need for new corporate performance evaluation and reporting systems. Bus. Strat Environ. 15, 296-308. https://doi.org/10.1002/bse.538.

Pham, H., Sutton, B.G., Brown, P.J., Brown, D.A., 2020. Moving towards sustainability: a theoretical design of environmental performance measurement systems. J. Clean. Prod. 269, 122273.

Rodrigue, M., Magnan, M., Boulianne, E., 2013. Stakeholders' influence on environmental strategy and performance indicators: a managerial perspective. Manag. Account. Res. 24, 301-316. https://doi.org/10.1016/j.mar.2013.06.004.

Rodrigues, V.P., Pigosso, D.C.A., McAloone, T.C., 2016. Process-related key performance indicators for measuring sustainability performance of eco-design implementation into product development. J. Clean. Prod. 139, 416-428. https://doi.org/10.1016/j.jclepro.2016.08.046.

Scavone, G.M., 2006. Challenges in internal environmental management reporting in Argentina. J. Clean. Prod. 14, 1276-1285. https://doi.org/10.1016/ j.jclepro.2005.08.011.

Schneider, A., Meins, E., 2012. Two dimensions of corporate sustainability assessment: towards a comprehensive framework. Bus. Strat. Environ. 21, 211-222. https://doi.org/10.1002/bse.726.

Schöggl, J.P., Fritz, M.M.C., Baumgartner, R.J., 2016. Toward supply chain-wide sustainability assessment: a conceptual framework and an aggregation method to assess supply chain performance. J. Clean. Prod. 131, 822-835. https://doi.org/ 10.1016/j.jclepro.2016.04.035.

Searcy, C., 2012. Corporate sustainability performance measurement systems: a review and research agenda. J. Bus. Ethics 107, 239-253. https://doi.org/ 10.1007/s10551-011-1038-z. 
Searcy, C., 2016. Measuring enterprise sustainability. Bus. Strat. Environ. 25, 120-133. https://doi.org/10.1002/bse.1861.

Seele, P., 2016. Digitally unified reporting: how XBRL-based real-time transparency helps in combining integrated sustainability reporting and performance control. J. Clean. Prod. 136, 65-77. https://doi.org/10.1016/j.jclepro.2016.01.102.

Seuring, S., Gold, S., 2013. Sustainability management beyond corporate boundaries: from stakeholders to performance. J. Clean. Prod. 56, 1-6. https://doi.org/ 10.1016/j.jclepro.2012.11.033.

Shahbazi, S., Jönsson, C., Wiktorsson, M., Kurdve, M., Bjelkemyr, M., 2018. Material efficiency measurements in manufacturing: Swedish case studies. J. Clean. Prod. 181, 17-32. https://doi.org/10.1016/j.jclepro.2018.01.215.

Sroufe, R., 2017. Integration and organizational change towards sustainability. J. Clean. Prod. 162, 315-329. https://doi.org/10.1016/j.jclepro.2017.05.180.

Trianni, A., Cagno, E., Neri, A., Howard, M., 2019. Measuring industrial sustainability performance: empirical evidence from Italian and German manufacturing small and medium enterprises. J. Clean. Prod. 229, 1355-1376. https://doi.org/ 10.1016/j.jclepro.2019.05.076.

Trumpp, C., Endrikat, J., Zopf, C., Guenther, E., 2013. Definition, conceptualization, and measurement of corporate environmental performance: a critical examination of a multidimensional construct. J. Bus. Ethics 126, 185-204. https:// doi.org/10.1007/s10551-013-1931-8.

Varsei, M., Soosay, C., Fahimnia, B., Sarkis, J., 2014. Framing sustainability performance of supply chains with multidimensional indicators. Supply Chain Manag. 19, 242-257. https://doi.org/10.1108/SCM-12-2013-0436.

Venturelli, A., Caputo, F., Leopizzi, R., Mastroleo, G., 2017. How can CSR identity be evaluated? A pilot study using a Fuzzy Expert System. J. Clean. Prod. 141, 1000-1010. https://doi.org/10.1016/j.jclepro.2016.09.172.

Virtanen, T., Tuomaala, M., Pentti, E., 2013. Energy efficiency complexities: a technical and managerial investigation. Manag. Account. Res. 24, 401-416. https:// doi.org/10.1016/j.mar.2013.06.002.

Wu, L., Subramanian, N., Gunasekaran, A., Abdulrahman, M.D.A., Pawar, K.S., Doran, D., 2018. A two-dimensional, two-level framework for achieving corporate sustainable development: assessing the return on sustainability initiatives. Bus. Strat. Environ. 27, 1117-1130. https://doi.org/10.1002/bse.2055.

Xia, D., Yu, Q., Gao, Q., Cheng, G., 2017. Sustainable technology selection decisionmaking model for enterprise in supply chain: based on a modified strategic balanced scorecard. J. Clean. Prod. 141, 1337-1348. https://doi.org/10.1016/ j.jclepro.2016.09.083.

Xie, S., Hayase, K., 2007. Corporate environmental performance evaluation: a measurement model and a new concept. Bus. Strat. Environ. 168, 148-168. https://doi.org/10.1002/bse.

Yin, H., Schmeidler, P.J., 2008. Why do standardized ISO 14001 environmental management systems lead to heterogeneous environmental outcomes? Bus. Strat. Environ. 18 (7), 469-486. https://doi.org/10.1002/bse.629.

\section{Additional References}

Aguinis, H., 2012. Performance Management, third ed. Pearson, Harlow.

Albertini, E., 2013. Does environmental management improve financial performance? A meta-analytical review. Organ. Environ. 26, 431-457. https://doi.org/ $10.1177 / 1086026613510301$.

Armstrong, M.E., Baron, A., 2005. Managing Performance: Performance Management in Action. CIPD, London.

Cheng, W., Appolloni, A., D’Amato, A., Zhu, Q., 2018. Green Public Procurement, missing concepts and future trends-A critical review. J. Clean. Prod. 176, $770-784$.

Farias, L.M.S., Santos, L.C., Gohr, C.F., de Oliveira, L.C., da Silva Amorim, M.H., 2019. Criteria and practices for lean and green performance assessment: systematic review and conceptual framework. J. Clean. Prod. 218, 746-762. https://doi.org/ 10.1016/j.jclepro.2019.02.042.

Ferreira, A., Otley, D., 2009. The design and use of performance management systems: an extended framework for analysis. Manag. Account. Res. 20 (4), 263-282. https://doi.org/10.1016/j.mar.2009.07.003.

Gond, J.P., Grubnic, S., Herzig, C., Moon, J., 2012. Configuring management control systems: theorizing the integration of strategy and sustainability. Manag. Account. Res. 23, 205-223. https://doi.org/10.1016/j.mar.2012.06.003.

Haider, H., Sadiq, R., Tesfamariam, S., 2016. Intra-utility performance management model (In-UPM) for the sustainability of small to medium sized water utilities: conceptualization to development. J. Clean. Prod. 133, 777-794. https://doi.org/ 10.1016/j.jclepro.2016.06.003.

Harwood, T.G., Garry, T., 2003. An overview of content analysis. Market. Rev. 3 (4), $479 \mathrm{e} 498$.

Hristov, I., Chirico, A., Appolloni, A., 2019. Sustainability value creation, survival, and growth of the company: a critical perspective in the sustainability balanced scorecard (SBSC). Sustainability 11, 2119. https://doi.org/10.3390/su11072119.

Jarden, R.J., Narayanan, A., Sandham, M., Siegert, R.J., Koziol-Mclain, J., 2019. Bibliometric mapping of intensive care nurses' wellbeing: development and application of the new iAnalysis model. BMC Nurs. 18, 1-11. https://doi.org/ 10.1186/s12912-019-0343-1.

Kohlbacher, F., 2006. The use of qualitative content analysis in case study research. Forum Qual. Soc. Res. 7 (1), 21.

Kolk, A., Mauser, A., 2002. The evolution of environmental management: from stage models to performance evaluation. Bus. Strat. Environ. 11, 14-31. https:// doi.org/10.1002/bse.316.

Leximancer, 2018. Leximancer user guide. Release 4, 1-136.

Littell, J.H., Corcoran, J., Pillai, V., 2008. Systematic Reviews and Meta-Analysis, Oxford University Press, New York.

Liu, L., Wu, T., Li, S., de Jong, M., Sun, Y., 2017. The drivers of local environmental policy in China: an analysis of Shenzhen's environmental performance management system, 2007-2015. J. Clean. Prod. 165, 656-666. https://doi.org/ 10.1016/j.jclepro.2017.07.165.

Lo, S., Sheu, H., 2007. Is corporate sustainability a value-increasing strategy for business? Corp. Govern. Int. Rev. 15, 345-358.

Morioka, S.N., de Carvalho, M.M., 2017. Discussing sustainability in business context and in performance disclosures: analysis of Brazilian case studies. Gestão Produção 24, 514-525. https://doi.org/10.1590/0104-530X2665-16.

Parker, L.D., 2012. Qualitative management accounting research: assessing deliverables and relevance. Crit. Perspect. Account. 23 (1), 54-70.

Pickering, C., Byrne, J., 2014. The benefits of publishing systematic quantitative literature reviews for $\mathrm{PhD}$ candidates and other early-career researchers. High Educ. Res. Dev. 33 (3), 534e548.

Purvis, B., Mao, Y., Robinson, D., 2019. Three pillars of sustainability: in search of conceptual origins. Sustain. Sci. 14, 681-695.

Schaltegger, S., Burritt, R.L., 2010. Sustainability accounting for companies: catchphrase or decision support for business leaders? J. World Bus. 45, 375-384 https://doi.org/10.1016/j.jwb.2009.08.002.

Seuring, S., Müller, M., 2008. From a literature review to a conceptual framework for sustainable supply chain management. J. Clean. Prod. 16, 1699-1710. https:// doi.org/10.1016/j.jclepro.2008.04.020.

Smith, A.E., Humphreys, M.S., 2006. Evaluation of unsupervised semantic mapping of natural language with leximancer concept mapping. Behav. Res. Methods 38 (2), 262-279.

Tranfield, D., Denyer, D., Smart, P., 2003. Towards a methodology for developing evidence-informed management knowledge by means of systematic review. Br. J. Manag. 14, 207-222. https://doi.org/10.1111/1467-8551.00375. 